\title{
Downregulation of Transient Receptor Potential Melastatin 8 by Protein Kinase C-Mediated Dephosphorylation
}

\author{
Louis S. Premkumar, Manish Raisinghani, Sandeep C. Pingle, Cheng Long, and Fátima Pimentel \\ Department of Pharmacology, Southern Illinois University School of Medicine, Springfield, Illinois 62702
}

Transient receptor potential melastatin 8 (TRPM8) and transient receptor potential vanilloid 1 (TRPV1) are ion channels that detect cold and hot sensations, respectively. Their activation depolarizes the peripheral nerve terminals resulting in action potentials that propagate to brain via the spinal cord. These receptors also play a significant role in synaptic transmission between dorsal root ganglion (DRG) and dorsal horn (DH) neurons. Here, we show that TRPM8 is functionally downregulated by activation of protein kinase C (PKC) resulting in inhibition of membrane currents and increases in intracellular $\mathrm{Ca}^{2+}$ compared with upregulation of TRPV1 in cloned and native receptors. Bradykinin significantly downregulates TRPM8 via activation of PKC in DRG neurons. Activation of TRPM8 or TRPV1 at first sensory synapse between DRG and DH neurons leads to a robust increase in frequency of spontaneous/miniature EPSCs. PKC activation blunts TRPM8- and facilitates TRPV1-mediated synaptic transmission. Significantly, downregulation is attributable to PKC-mediated dephosphorylation of TRPM8 that could be reversed by phosphatase inhibitors. These findings suggest that inflammatory thermal hyperalgesia mediated by TRPV1 may be further aggravated by downregulation of TRPM8, because the latter could mediate the much needed cool/soothing sensation.

Key words: bradykinin; TRPM8; TRPV1; nociceptor; synaptic transmission; protein kinase C; channel; c-fiber

\section{Introduction}

The transient receptor potential (TRP) family of ion channels responds to physical and chemical stimuli (Caterina et al., 1997; Minke and Cook, 2002; Clapham, 2003; Montell, 2005). Transient receptor potential melastatin 8 (TRPM8) and transient receptor potential vanilloid 1 (TRPV1) are $\mathrm{Ca}^{2+}$ permeant nonspecific cation channels expressed in subpopulations of primary afferent neurons. TRPM8 is activated by cold $\left(<25^{\circ} \mathrm{C}\right)$ and agents like menthol (an active ingredient of peppermint), icilin, and eucalyptol, which induce a cool/soothing sensation (McKemy et al., 2002; Peier et al., 2002; Reid et al., 2002). Not only does TRPM8 sense temperature at the periphery, but it also mediates synaptic transmission at the first sensory synapse between dorsal root ganglion (DRG) and dorsal horn (DH) neurons in the spinal cord (Baccei et al., 2003; Tsuzuki et al., 2004). In contrast, TRPV1 is activated by heat $\left(>42^{\circ} \mathrm{C}\right)$, protons, $N$-arachidonoyldopamine, anandamide, and lipoxygenase products and is involved in the detection of inflammatory thermal pain (Caterina et al., 1997; Tominaga et al., 1998; Hwang et al., 2000; Chuang et al., 2001; Julius and Basbaum, 2001; Huang et al., 2002). Distribution of

Received July 20, 2005; revised 0ct. 20, 2005; accepted 0ct. 21, 2005.

This work was supported by National Institutes of Health Grants NSO42296 and DK065742 and Southern Illinois University Excellence in Academic Medicine Award to L.S.P. TRPV1 and TRPM8 CDNA clones were gifts from D. Julius. (University of California, San Francisco, San Francisco, CA). TRPV1 double mutant was a gift from M. Tominaga (Okazaki Institute for Integrative Bioscience, Okazaki, Japan).

Correspondence should be addressed to Louis S. Premkumar, Department of Pharmacology, Southern Illinois University School of Medicine, 801 North Rutledge Street, Springfield, IL 62702. E-mail: Ipremkumar@siumed.edu.

S. C. Pingle's present address: Department of Pharmacology, Georgetown University, Washington, DC 20007.

C. Long's present address: Molecular Physiology and Biophysics, Baylor College of Medicine, Houston, TX 77030

D01:10.1523/JNEUROSCI.3006-05.2005

Copyright $\odot 2005$ Society for Neuroscience $\quad$ 0270-6474/05/2511322-08\$15.00/0
TRPM8 and TRPV1 in areas that are not subjected to these temperature ranges suggests a role beyond that as temperature sensors (Manzini, 1992; Zygmunt et al., 1999; Mezey et al., 2000; Birder et al., 2002; Baccei et al., 2003; Tsuzuki et al., 2004). TRPM8 (previously identified as Trp-p8) is upregulated in prostate cancer and is involved in urinary bladder function, which broadens the horizon of TRPM8 in other pathophysiological conditions (Tsavaler et al., 2001). In addition to TRPM8, another cold temperature sensor (transient receptor potential ankyrin) has been cloned recently, activation of which is implicated in noxious cold sensation (Story et al., 2003). Protein kinase C (PKC) is known to modulate activity of several ion channels. Potentiation of TRPV1 by PKC and agonists like bradykinin (BK) has been studied extensively (Lopshire and Nicol, 1998; Cesare et al., 1999a,b; Khasar et al., 1999; Premkumar and Ahern, 2000; Numazaki et al., 2002). Here, we demonstrate a functional downregulation of TRPM8 by activation of $\mathrm{PKC}$ resulting in inhibition of TRPM8-mediated channel activity and synaptic transmission in contrast to TRPV1, which is upregulated. These effects are attributable to PKC-initiated dephosphorylation of TRPM8 by activation of protein phosphatases.

\section{Materials and Methods}

Electrophysiology. Defolliculated Xenopus laevis oocytes were injected with 1-5 ng of TRPM8 or TRPV1 wild-type and mutant cRNA (Premkumar and Ahern, 2000). Animals were cared for according to the standards of the National Institutes of Health. All protocols for animal use were approved by the Animal Care Committee at Southern Illinois University School of Medicine. Double electrode voltage-clamp experiments were performed using a Warner amplifier (OC725C; Warner Instruments, Hamden, CT) with $100 \%$ DC gain. All of the experiments were performed at $21-23^{\circ} \mathrm{C}$. Oocytes were placed in a Perspex chamber and 
continuously superfused (5-10 ml/min) with $\mathrm{Ca}^{2+}$-free Ringer's solution containing the following (in mM): $100 \mathrm{NaCl}, 2.5 \mathrm{KCl}, 5 \mathrm{HEPES}, \mathrm{pH}$ adjusted to 7.35 , with $\mathrm{NaOH}$. $\mathrm{Ca}^{2+}$-free conditions were used to minimize tachyphylaxis and contamination from $\mathrm{Ca}^{2+}$-activated $\mathrm{Cl}^{-}$currents. Electrodes were filled with $3 \mathrm{M} \mathrm{KCl}$ and had resistance of 5-15 $\mathrm{m} \Omega$. $I-V$ relationships were measured using voltage ramps from -80 to +80 $\mathrm{mV}$. For single-channel recordings, the bath solution contained the following (in mM): $100 \mathrm{~K}$ gluconate, $10 \mathrm{NaCl}, 5 \mathrm{HEPES}$, and $1.5 \mathrm{EGTA}, \mathrm{pH}$ 7.35. The patch pipettes were made from glass capillaries (Microcaps; Drummond, Broomall, PA) coated with sylgard (Dow Corning, Midland, MI) and filled with a solution that contained the following (in mM): $90 \mathrm{Na}$ gluconate, $10 \mathrm{NaCl}, 1.5 \mathrm{EGTA}, 1 \mathrm{MgCl}_{2}$, and 10 HEPES, pH 7.35. Currents were recorded using a WPC 100 patch-clamp amplifier (E.S.F. Electronic, Goettingan, Germany). Data were filtered at $10 \mathrm{kHz}$, digitized (VR-10B; Instrutech, Great Neck, NY), and stored on videotapes. For analysis, data were filtered at $2.5 \mathrm{kHz}$ ( $-3 \mathrm{db}$ frequency with an eight-pole low-pass Bessel filter; LPF-8; Warner Instruments) and digitized at $5 \mathrm{kHz}$.

The current responses to cold temperatures were recorded by directing a continuously flowing cold solution onto the oocytes by activating a solenoid valve at the entry of the oocyte chamber. The temperature of the solution was maintained by immersing the reservoir in ice, and the solution flow tube was kept cold by immersing it in the melting solution from the ice flowing in an outer jacket. Using this technique, we were able to record both the current and the temperature change consistently.

DRG and DH neurons were isolated from embryonic day 18 (E18) rat pups, triturated, and cultured in neurobasal medium supplemented with B-27 (a serum-free supplement) and glutamine (Invitrogen, Grand Island, NY) on poly-D-lysine-coated glass coverslips. Dissociated neurons were obtained from postnatal day 10 (P10) to P21 Sprague Dawley rats. Briefly, harvested DRGs were digested with trypsin $(1 \mathrm{mg} / \mathrm{ml})$ and collagenase $(1 \mathrm{mg} / \mathrm{ml})$ for $1 \mathrm{~h}$, followed by trituration. The cells were transferred to an enzyme-free neurobasal medium and plated on poly-Dlysine-coated coverslips and used within 18-36 h. For perforated-patch recordings, the bath solution contained (in $\mathrm{mm}$ ) $140 \mathrm{Na}$ gluconate, 2.5 $\mathrm{KCl}, 10 \mathrm{HEPES}, 1 \mathrm{MgCl}_{2}, 1.5 \mathrm{EGTA}$, pH 7.35, and the pipette solution contained (in mM) $130 \mathrm{Na}$ gluconate, $10 \mathrm{NaCl}, 2.5 \mathrm{KCl}$, 10 HEPES, 1 $\mathrm{MgCl}_{2}, 1.5 \mathrm{EGTA}$, and amphotericin B $(240 \mu \mathrm{g} / \mathrm{ml})$. Currents were recorded using a WPC 100 patch-clamp amplifier (E.S.F. Electronic) or EPC10 (HEKA, Lambrecht, Germany). Data were filtered at $10 \mathrm{kHz}$, digitized (VR-10B), and stored on videotapes. For analysis, data were filtered at $2.5 \mathrm{kHz}(\mathrm{LPF}-8)$ and digitized at $5 \mathrm{kHz}$.

For synaptic current recordings, DRG (rounded) and DH (pyramidal) neurons were identified by their morphology. DRG neurons do not exhibit synaptic currents, whereas DH neurons show excitatory and inhibitory synaptic currents. The extracellular bath solution contained (in mм) $140 \mathrm{NaCl}, 4 \mathrm{KCl}, 1 \mathrm{MgCl}_{2}, 1.8 \mathrm{CaCl}_{2}, 10$ HEPES, 5 D-glucose, $\mathrm{pH}$ 7.35 , and the pipette solution contained (in $\mathrm{mm}$ ) $130 \mathrm{~K}$ gluconate, 10 $\mathrm{NaCl}, 1 \mathrm{MgCl}_{2}, 0.2$ EGTA, 10 HEPES, 1 ATP, $\mathrm{pH}$ adjusted to 7.35, with $\mathrm{KOH}$. To record fast EPSCs, DH neurons were voltage clamped (EPC10; HEKA) at $-60 \mathrm{mV}$ (close to $\mathrm{E}_{\mathrm{Cl}}$ ). While recording miniature EPSCs (mEPSCs), the bath solution contained lidocaine (10 mM), bicuculline $(20 \mu \mathrm{M})$, and strychnine $(1 \mu \mathrm{M})$. Application of DNQX $(20 \mu \mathrm{M})$ completely abolished the synaptic currents. The data were filtered at $2.5 \mathrm{kHz}$ and digitized at $5 \mathrm{kHz}$. Data were analyzed using Mini Analysis Program (Synaptosoft, Decatur, GA). The amplitude and frequency of the events were determined from $30 \mathrm{~s}$ data segments to avoid desensitization of responses over time.

$\mathrm{Ca}^{2+}$ imaging. DRG neurons grown on glass coverslips were incubated with $3 \mu \mathrm{M}$ Fluo-4 AM (Invitrogen, Eugene, OR) for $20 \mathrm{~min}$ at $37^{\circ} \mathrm{C}$ and washed with physiological buffer containing the following (in mM): 140 $\mathrm{NaCl}, 5 \mathrm{HEPES}, 2 \mathrm{CaCl}_{2}, 1 \mathrm{MgCl}_{2}, 2.5 \mathrm{KCl}, 2$ Lidocaine, $\mathrm{pH}$ 7.35. Fluo-4 was excited at $488 \mathrm{~nm}$, and emitted fluorescence was filtered with a $535 \pm$ $25 \mathrm{~nm}$ bandpass filter and read into a computer running Scanalytics software (Scanalytics, Fairfax, VA). Multiple cells were selected (DMIRE2; Leica, Plymouth, MN), and the fluorescence of individual cells was tracked. The ratio of the fluorescence change $F / F_{\mathrm{o}}$ was plotted to represent the change in intracellular $\mathrm{Ca}^{2+}$ levels. The chamber was continuously perfused with control solution, and the different solutions were applied by controlling a solenoid valve, which occluded the flow of the control solution and started the flow of test solution.

Immunoprecipitation/Western blotting. Oocytes or human embryonic kidney 293T (HEK293T) cells expressing FLAG-TRPM8 were lysed using cell lysis buffer (20 mM Tris, $150 \mathrm{~mm} \mathrm{NaCl}, 1$ mm EDTA, 1 mm EGTA, and $1 \%$ Triton X-100). Whole-cell lysates were used for immunoprecipitation. In the initial step, after preclearing with normal mouse IgG, cell lysates were incubated with $2 \mu$ g of primary antibody (FLAG-M2; Sigma, St. Louis, MO) overnight at $4^{\circ} \mathrm{C}$, followed by Protein A/G-agarose conjugate suspension for $4 \mathrm{~h}$ at $4^{\circ} \mathrm{C}$. The pellet was collected by centrifugation and washed four times with cell lysis buffer (stringent wash). The pellet was reconstituted in $2 \times$ electrophoresis sample buffer and boiled for $5 \mathrm{~min}$. This sample was then used for SDS-PAGE/Western blotting. Proteins were transferred to nitrocellulose membranes, blocked in Blotto buffer (130 mm NaCl, $2.7 \mathrm{~mm} \mathrm{KCl,} 1.8 \mathrm{~mm} \mathrm{Na}_{2} \mathrm{HPO}_{4}, 1.5 \mathrm{~mm} \mathrm{K \textrm {H } _ { 2 }} \mathrm{PO}_{4}$, $0.1 \% \mathrm{NaN}_{3}, 0.1 \%$ Triton X-100, and $5 \%$ low-fat skim milk) for $2 \mathrm{~h}$, and then incubated overnight with the primary antibody (p-serine; Sigma), FLAG-M2 at $4^{\circ} \mathrm{C}$. After five washes in blocking solution, blots were incubated in horseradish peroxidase (HRP)-labeled IgG (Amersham Biosciences, Piscataway, NJ) for $1 \mathrm{~h}$ at room temperature, washed five times, treated with Western blotting detection reagents (ECL Plus; Amersham Biosciences), and exposed to Kodak (Rochester, NY) XAR film at room temperature. Quantification of the gels was performed using Scion Image Beta 4.0.2 software (Scion, Frederick, MD).

Measurement of nocifensive behavior. The experiments were performed according to the National Institutes of Health guidelines and approved by the animal welfare committee of Southern Illinois University School of Medicine. Nocifensive behavior was examined in mice after intraplantar injection of TRPV1 and TRPM8 agonists capsaicin and menthol, respectively. Nocifensive behavior was characterized by the latency, duration, and number of licking and/or shaking of the injected hindlimb.

All of the chemicals used in this study were obtained from Sigma. The working concentration of capsaicin, menthol, and phorbol-12,13dibutyrate $(\mathrm{PDBu})$ were prepared fresh before the experiments from an ethanol stock. Bisindolylmaleimide (BIM) and chelerythrine were made in DMSO. The maximum concentration of ethanol and DMSO were $<0.01$ and $0.02 \%$, respectively. Data are represented as mean \pm SEM. Student's $t$ test was used for statistical comparisons, and the significance was considered at $p<0.05$.

\section{Results}

\section{Downregulation of cloned TRPM8 by PKC}

Menthol-evoked currents mediated by cloned TRPM8 heterologously expressed in Xenopus oocytes were significantly reduced (30 $\mu \mathrm{M}$ menthol, $88.3 \pm 3.8 ; 100 \mu \mathrm{M}$ menthol, $75.2 \pm 6 \% ; n=17$ ) by incubating with PDBu, a PKC activator ( $1 \mu \mathrm{M} ; 5 \mathrm{~min}$ ) (Fig. $1 a, j)$. Figure $1 b$ shows the time course of PDBu-induced downregulation, which attained maximum at 5 min exposure and reversed over a period of $10 \mathrm{~min}$. Increasing the concentration of $\mathrm{PDBu}$ from 0.01 to $1 \mu \mathrm{M}$ showed a graded response maximizing at $1 \mu \mathrm{M}$ (Fig. 1c). At lower concentrations (0.01-0.1 $\mu \mathrm{M})$ of $\mathrm{PDBu}$, there was a slight increase in the current amplitude, which was not statistically significant. We used another PKC activator, phorbol 12-myristate, 13-acetate (PMA; $1 \mu \mathrm{M} ; 5 \mathrm{~min}$ ), which showed a similar effect as PDBu (100 $\mu \mathrm{M}$ menthol, $88.3 \pm 3.8 \%$; $n=7$ ) (Fig. $1 j$ ) but took longer for the effect to reverse. Similarly, cold temperature-induced $\left(22-16^{\circ} \mathrm{C}\right)$ TRPM8 currents were also reduced by $>80 \%$ by $\mathrm{PDBu}(87 \pm 4.6 \% ; n=4)($ Fig. $1 d, j)$. Not only the amplitude but also the activation temperature of coldinduced current was reduced (from $18.08 \pm 0.15$ to $17.12 \pm$ $0.21^{\circ} \mathrm{C} ; n=4 ; p>0.05$ ) after PDBu (Fig. 1e). These responses were specific to TRPM8, because uninjected oocytes or oocytes injected with cRNA other than those of TRPM8 did not respond to menthol or cold. Dose-response curves of menthol-induced currents exhibited a rightward shift and an increase in the $\mathrm{EC}_{50}$ value from 56 to $156 \mu \mathrm{M}$, without altering the maximal response, 
which suggests that the sensitivity of TRPM8 is reduced after PDBu (Fig. 1f). A ramp protocol showed that outwardly rectifying TRPM8 current induced by menthol is reduced after PDBu at both positive and negative potentials and reverses close to $0 \mathrm{mV}(2.2 \mathrm{mV}$ ) (Fig. $1 g$ ), suggesting that $\mathrm{PDBu}$ does not alter only the rectification properties. PKC inhibitors BIM $(0.5 \mu \mathrm{M})$ or chelerythrine $(20 \mu \mathrm{M})$ abolished the reduction of TRPM8-mediated currents by $\mathrm{PDBu}(30 \mu \mathrm{M}$ menthol, $7.2 \pm 5.2 \%, n=5$ and $12.6 \pm 14.6 \%, n=3$, respectively) confirming PKC-mediated inhibition of TRPM8 (Fig. $1 h, j$ ). Next, we used oocytes injected with both TRPM8 and TRPV1 cRNA. Incubation of oocytes with PDBu resulted in a significant reduction of menthol-induced currents $(30 \mu \mathrm{M}$ menthol, $79.4 \pm 2.4 \% ; n=3$ ) (Fig. 1i) but a several-fold potentiation of capsaicininduced currents (30 nM capsaicin, $12.1 \pm$ 6.3 fold; $n=4$ ) (Fig. 1i,k), which could be blocked by BIM ( $3.3 \pm 1$ fold; $n=3)$. In oocytes expressing TRPV1 alone, currents exhibited a substantial potentiation after $\mathrm{PDBu}$ (30 nM capsaicin, $24.3 \pm 2.3$ fold; $n=3$ ), which could be abolished by a double phosphorylation site mutant (supplemental Fig. 1, available at www.jneurosci. org as supplemental material). These results indicate that the activation of PKC downregulates TRPM8 but upregulates TRPV1-mediated currents.

We also studied the modulation of TRPM8 at a single-channel level. In cellattached patches, menthol-induced currents showed profound outward rectification, which is attributable to voltage dependence of open probability. The $P_{\mathrm{o}}$ at negative potentials tended to be very low to make meaningful conclusions. Hence, we analyzed the $P_{\mathrm{o}}$ at positive potentials before and after PDBu application and during washout. The $P_{\mathrm{o}}$ decreased significantly after $\mathrm{PDBu}(1 \mu \mathrm{M} ; 5 \mathrm{~min})$ (before, $0.13 \pm 0.01$; after, $0.06 \pm 0.02 ; n=4)$, and the responses could be partially reversed over time (Fig. 2).

\section{Downregulation of native TRPM8 \\ by PKC}

We also determined whether this effect is seen in native receptors expressed in cultured embryonic and adult dissociated DRG neurons using $\mathrm{Ca}^{2+}$ fluorescence imaging and patch-clamp techniques. Figure $3 a$ shows changes in intracellular $\mathrm{Ca}^{2+}$ when a group of neurons was exposed to menthol $(30 \mu \mathrm{M})$ and capsaicin $(100 \mathrm{nM})$ before and after PDBu. Of the total number of neurons (765), 8\% (61) responded to menthol, and $12 \%$ (90) responded to

a

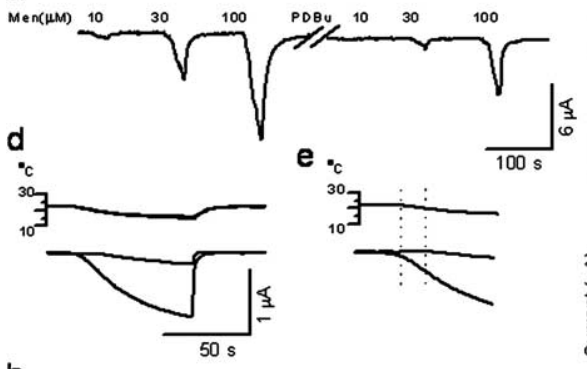

h

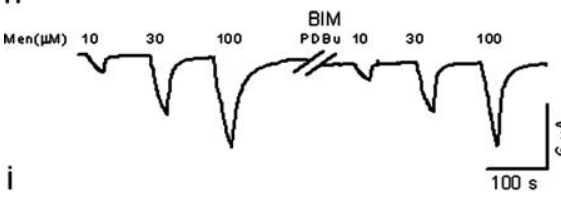

$M \ln (\mu M) 10$
$\operatorname{Cap(nM)}$
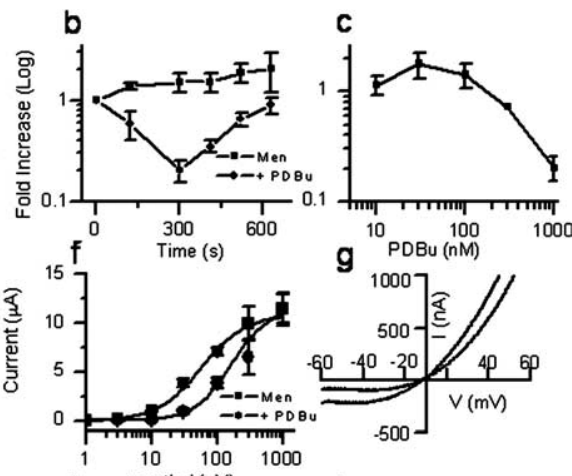

(9)
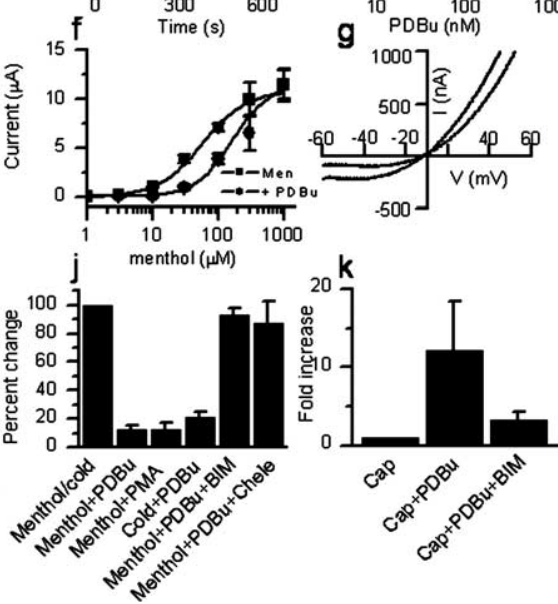

Figure 1. Reciprocal modulation of TRPM8- and TRPV1-mediated currents by PKC in Xenopus 0ocytes expressing TRPM8 and TRPV1. $\boldsymbol{a}$, Menthol-induced responses were reduced significantly by pretreatment with $\mathrm{PDBu}(1 \mu \mathrm{m} ; 5$ min denoted by a break in the trace). $\boldsymbol{b}$, Time course of PDBu-induced downregulation of TRPM8. $\boldsymbol{c}$, Dose-response curve of PDBu-induced downregulation. $\boldsymbol{d}$, Cold temperature $\left(15-22^{\circ} \mathrm{C}\right)$-induced currents were significantly reduced by PDBu. $\boldsymbol{e}$, Not only is the amplitude of cold currents reduced, but the activation threshold is reduced also (shifted from $18.08 \pm 0.15$ to $17.12 \pm 0.21^{\circ} c ; n=4 ; p<0.01$ ) (dotted lines). $\boldsymbol{f}$, Dose-response curves showing reduced sensitivity of the receptor after PDBu treatment; the $\mathrm{EC}_{50}$ value shifted from 56 to $156 \mu \mathrm{M} . \boldsymbol{g}$, I-V curve showing a ramp protocol that the TRPM8 current is rectifying and the block is seen at both positive and negative potentials before and after treatment with PDBu. $\boldsymbol{h}$, Treatment with PKC inhibitor BIM reversed the reduction in current amplitude. $i$, In an oocyte injected with cRNA for both TRPM8 and TRPV1, the menthol-induced currents were significantly reduced $(p<0.001)$, whereas, capsaicin-induced currents were significantly potentiated $(p<0.05)$. $\boldsymbol{j}$, Summary graph showing menthol-and cold-induced responses are significantly reduced ( $p<0.001)$ by PDBu or PMA, and the effect is reversed by the PKC inhibitor BIM. $\boldsymbol{k}$, Summary graph showing capsaicin-induced currents are potentiated significantly $(p<0.01)$ and reversed by treatment with BIM. Cap, Capsaicin; Men, menthol. Data are represented as mean \pm SEM.

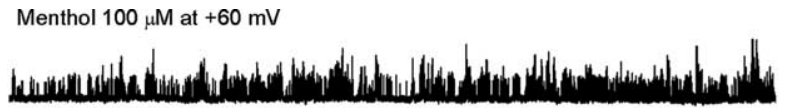

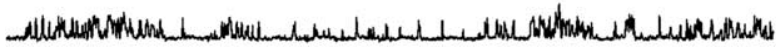

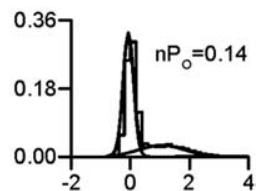

Menthol $100 \mu \mathrm{M}$ after PDBU $(1 \mu \mathrm{M})$ at $+60 \mathrm{mV}$

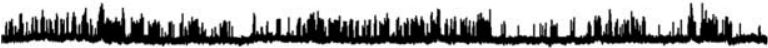

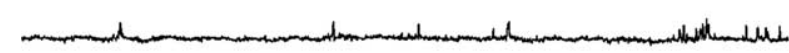

Menthol $100 \mu \mathrm{M}$ after wash at $+60 \mathrm{mV}$

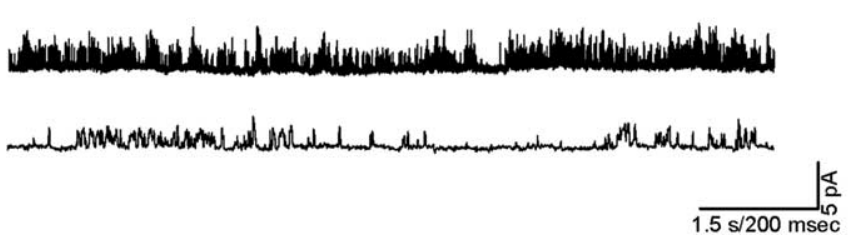

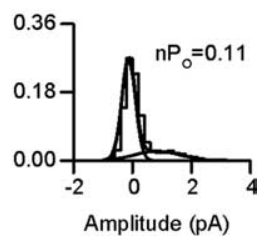

Figure 2. PKC activation blocks single-channel currents induced by menthol. Top, Single-channel currents activated by menthol at $+60 \mathrm{mV}$ from a cell-attached patch on an oocyte heterologously expressing TRPM8. Middle, Menthol-induced singlechannel activity is reduced by incubation with PDBu for $5 \mathrm{~min}$. Bottom, PDBu-induced reduction could be reversed after 5-10 min of washout. The right panel shows corresponding amplitude histograms, and the traces are shown at a higher time resolution below. 
a

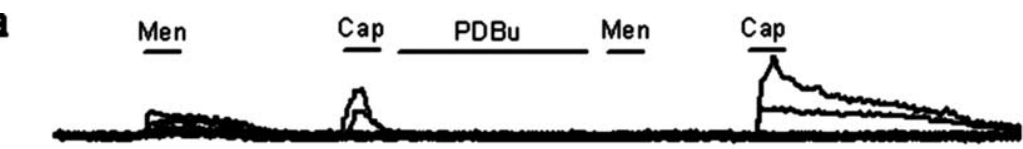

b

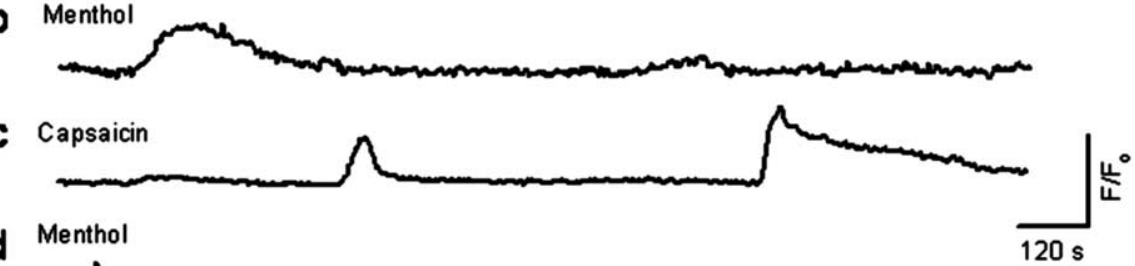

d

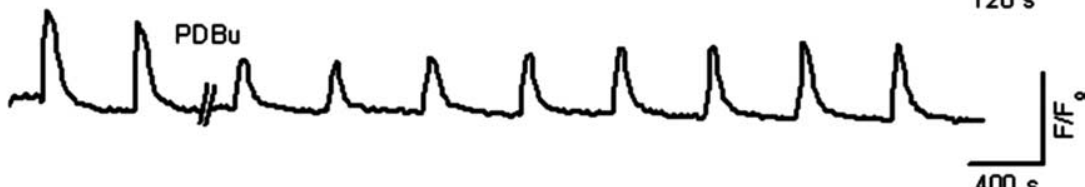

e

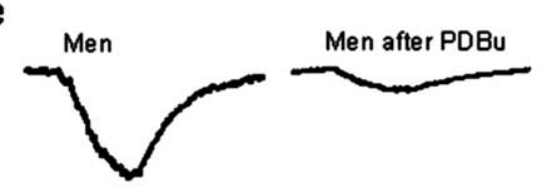

g

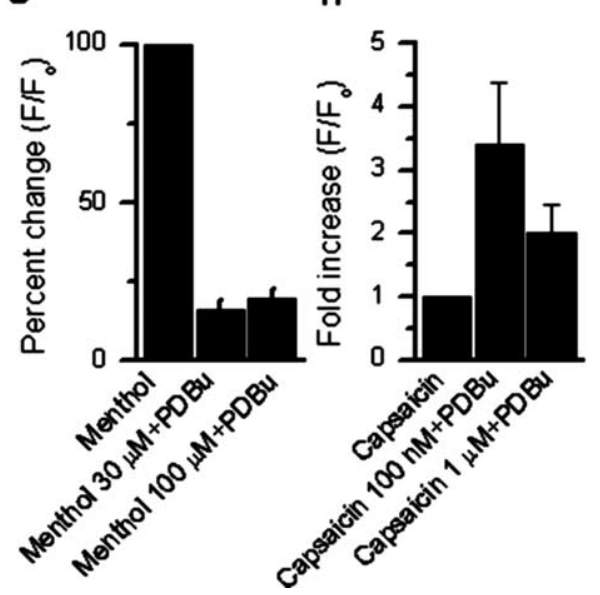

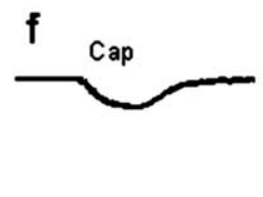

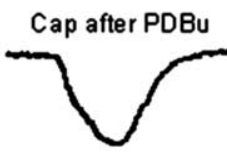

i

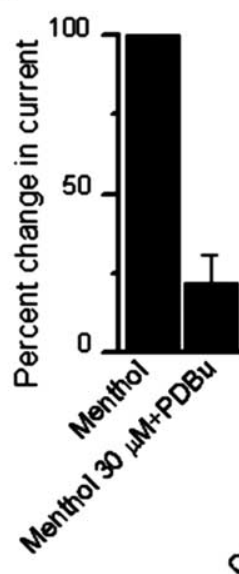

j

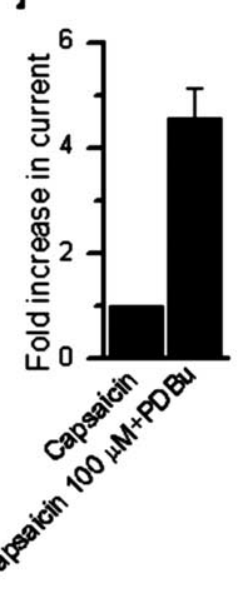

Figure 3. Menthol- and capsaicin-induced increases in intracellular $\mathrm{Ca}^{2+}$ levels and membrane currents in DRG neurons were reduced and enhanced, respectively, by PDBu $(1 \mu \mathrm{m}) . \boldsymbol{a}$, Twenty selected neurons in a coverslip were individually tracked for changes in intracellular $\mathrm{Ca}^{2+}$ levels $\left(F / F_{0}\right)$ while exposing them to menthol $(30 \mu \mathrm{M})$ and capsaicin $(100 \mathrm{~nm})$ before and after PDBu. Five neurons responded to menthol, two neurons responded to capsaicin, and one responded to both. Menthol responses were almost completely abolished ( $\boldsymbol{b}$ ), whereas capsaicin responses were significantly enhanced after PDBu (c). Note that capsaicin responses are larger and longer lasting. $\boldsymbol{d}$, Time course of PDBu induced downregulation of menthol (100 $\mu \mathrm{m})$-induced response. $\boldsymbol{e}$, Menthol (100 $\mu \mathrm{M})$-induced membrane currents were significantly reduced. $f$, Capsaicin ( $100 \mathrm{~nm})$-induced currents were significantly potentiated after pretreatment with PDBu. $\boldsymbol{g}, \boldsymbol{h}$, Summary graphs showing menthol-induced calcium responses are significantly reduced ( $p<0.01$ ), and capsaicin responses are significantly potentiated (100 nm capsaicin, $p<0.01 ; 1 \mu \mathrm{m}$ capsaicin, $p<0.05$ ) after PDBu. $i, j$, Summary graph showing significant inhibition $(p<0.01)$ of menthol-induced and significant potentiation $(p<0.01)$ of capsaicin-induced currents after PDBu. Cap, Capsaicin; Men, menthol. Data are represented as mean \pm SEM.

capsaicin and rarely responded to both menthol and capsaicin. Incubation with $\mathrm{PDBu}(1 \mu \mathrm{M} ; 5 \mathrm{~min})$ significantly reduced $(30 \mu \mathrm{M}$ menthol, $84 \pm 3 \%, n=10 ; 100 \mu \mathrm{M}$ menthol, $80 \pm 5 \%, n=51)$ and, in some neurons, completely abolished menthol-induced responses (Fig. 3a,b,g). In contrast, capsaicin-induced responses were potentiated significantly (100 nM capsaicin, $3.39 \pm 1, n=86 ; 1 \mu \mathrm{M}$ capsaicin, $2 \pm 0.47$ fold, $n=4$ ) (Fig. $3 a, c, h)$. Note that the decay phase of TRPV1 response was substantially prolonged after PDBu. We also determined the time course of PDBu action. Menthol-induced response, which was reduced following incubation with $\mathrm{PDBu}(1 \mu \mathrm{M}$; $5 \mathrm{~min}$ ) recovered over time (Fig. $3 d$ ). To further confirm that PKC downregulates TRPM8 and upregulates TRPV1 responses in DRG neurons, we recorded membrane currents. Similar to what was observed in oocytes, menthol $(30 \mu \mathrm{M})$-induced currents were significantly inhibited $(78 \pm 10 \% ; n=9)$ (Fig. $3 e, i)$, whereas capsaicin (100 nM)-induced currents were significantly potentiated $(4.6 \pm 0.6$-fold; $n=5)$ (Fig. 3f,j). These results confirm that activation of PKC in DRG neurons leads to a reduction in TRPM8mediated but potentiation of TRPV1-mediated responses.

$\mathrm{BK}$, an endogenous agonist, that activates PKC and is involved in sensitization of TRPV1 was used to study the effect of PKC activation on TRPM8 using $\mathrm{Ca}^{2+}$ fluorescence imaging in dissociated adult DRG neurons. We used concentrations of BK from 1 to $5 \mu \mathrm{M}$ and found that exposure of 5 $\mu \mathrm{M}$ for 2 min was ideal; higher concentrations and longer duration of application resulted in desensitization of BK receptors, indicated by reduced TRPV1- and TRPM8mediated modulation. TRPV1-mediated $\mathrm{Ca}^{2+}$ flux and its potentiation by BK was used as a positive control to confirm that PKC has been activated. Incubation of BK alone slightly increased the $\mathrm{Ca}^{2+}$ flux in some cells, which were not included in the analysis. Application of BK consistently downregulated TRPM8 $(44 \pm 4 \% ; n=13)$ but significantly potentiated TRPV1-mediated $\mathrm{Ca}^{2+}$ flux (4.6 \pm 1.4 fold; $n=10$ ) (Fig. $4 a, b)$. Note that the decay phase of potentiation of TRPV1 is significantly prolonged. BK-mediated decrease in TRPM8 response and increase in TRPV1 responses were almost completely reversed by BIM (500 nM); in fact, there was a slight increase in TRPM8 response (TRPM8, $110 \pm 8 \%, n=47$; TRPV1, $1.6 \pm 0.5$-fold, $n=17$ ) (Fig. $4 b$ ), validating the role of PKC modulation in a native system by an endogenous agonist.

\section{Modulation of TRPM8-mediated synaptic transmission by PKC} TRPM8 and TRPV1 are also distributed in central terminals of the sensory neurons, which synapse with the dorsal horn neurons in the spinal cord (Baccei et al., 2003; Tsuzuki et al., 2004). We determined whether activation of PKC alters TRPM8and TRPV1-mediated synaptic transmission at the first sensory synapse. In DRG and DH neuronal cocultures, DH neurons were voltage clamped and spontaneous EPSCs (sEPSCs) and mEPSCs were recorded in the absence or presence of lidocaine $(10 \mathrm{mM})$, respectively. The inhibitory postsynaptic currents were eliminated either by holding the neuron at $\mathrm{E}_{\mathrm{Cl}}$ or in the presence of bicuculline $(20 \mu \mathrm{M})$ and strychnine $(1 \mu \mathrm{M})$. Synaptic currents were completely abolished by DNQX (20 $\mu \mathrm{M})$ (data not shown). Application of menthol (30-100 $\mu \mathrm{M}$ ) (Fig. 5a) or capsaicin (30$100 \mathrm{nM}$ ) (Fig. 5e) robustly increased the frequency of mEPSCs. A menthol-induced increase in the frequency of mEPSCs (control, $104 \pm 32$; menthol, $710 \pm 244 ; n=8$ ) was profoundly reduced 
a
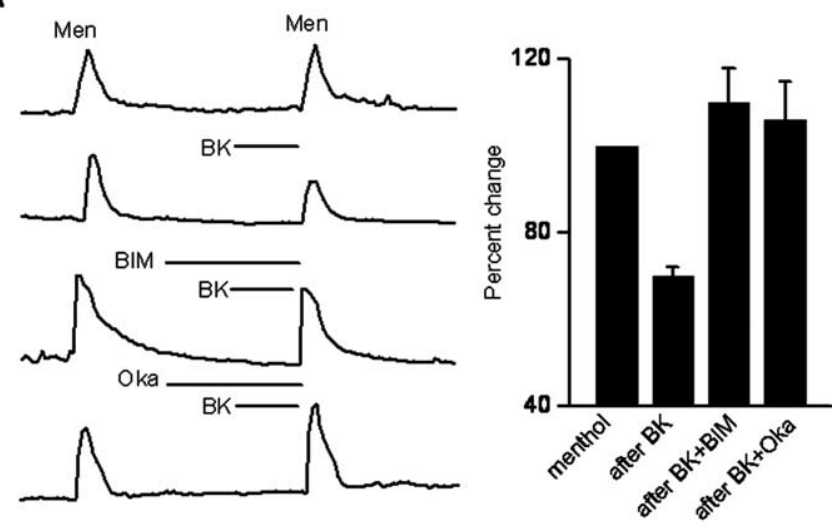

b

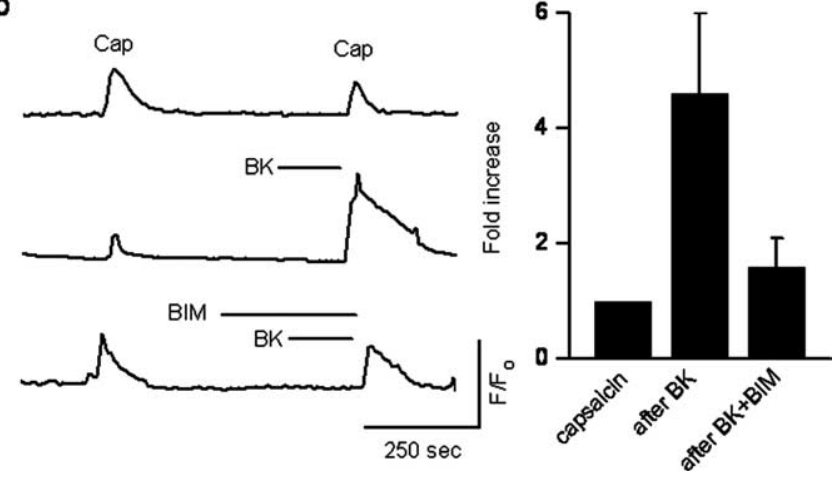

Figure 4. Reciprocal modulation of TRPM8 and TRPV1 by BK. $\boldsymbol{a}$, Exposure of dissociated adult DRG neurons to BK ( $5 \mu \mathrm{m} ; 2 \mathrm{~min}$ ) significantly decreased $\mathrm{Ca}^{2+}$ influx induced by menthol (100 $\mu \mathrm{m})(p<0.01)$. This response could be reversed by incubating the neurons with a specific PKC inhibitor, BIM (500 nM), or protein phosphatase 1 inhibitor, okadaic acid ( $20 \mathrm{~nm})$. $\boldsymbol{b}$, In similar experimental conditions, the capsaicin response is significantly $(p<0.01)$ potentiated by BIM. Cap, Capsaicin; Men, menthol; Oka, okadaic acid. Data are represented as mean $\pm \mathrm{SEM}$.

after incubating the neurons with $\mathrm{PDBu}(1 \mu \mathrm{M} ; 2 \mathrm{~min})$ after washout of PDBu induced increase in MEPSC frequency (173 \pm $47, n=8$ ), (Fig. $5 a, b, d$ ), and the responses were partially reversed after washout over time. There was no change in the amplitude of mEPSCs (control, $14.7 \pm 1.5$; menthol, $16.7 \pm 2.3$; menthol after PDBu, $15.8 \pm 2.2$ pA) (Fig. $5 c)(n=8)$. In contrast, PDBu further enhanced frequency of capsaicin-induced mEPSCs (control, $20 \pm 1$; capsaicin, $108 \pm 5$; capsaicin after PDBu, $272 \pm 13 ; n=$ 6) (Fig. $5 e, f, h$ ), without altering the amplitude (control, $14.3 \pm$ 2.1; capsaicin, $15.3 \pm 0.62$; capsaicin after $\mathrm{PDBu}, 16.5 \pm 0.48 ; n=$ $6 \mathrm{pA}$ ) (Fig. $5 g$ ). The reversible nature of $\mathrm{PDBu}$-induced increase in the frequency of mEPSCs (Leenders and Sheng, 2005; Lou et al., 2005) did not interfere with our experiments, because PKCmediated phosphorylation of TRPM8 and TRPV1 lasted longer to modulate agonist-induced changes in synaptic currents than the direct action of PDBu on the release apparatus. Menthol- and capsaicin-induced changes in synaptic transmission were seen only in DRG-DH cocultures but not in DH-only cultures. In DRG-only cultures, there were no synaptic events. Furthermore, only the frequency was altered, not the amplitude, suggesting modulation of transmitter release from the central terminals of the DRG neurons. In summary, menthol-mediated synaptic transmission is profoundly reduced, whereas that resulting from capsaicin is significantly enhanced by activation of PKC. These results indicate that PKC plays a significant role in TRPM8- and TRPV1-mediated neurotransmission at the first sensory synapse.
Mechanism of PKC-mediated downregulation of TRPM8

Phosphorylation of TRPV1 has been studied extensively (Lopshire and Nicol, 1998; Cesare et al., 1999a,b; Khasar et al., 1999; Premkumar and Ahern, 2000; Numazaki et al., 2002). Mutation of S502A and S800A almost completely abolished PDBumediated potentiation of proton- and capsaicin-induced currents (supplemental Fig. 1, available at www.jneurosci.org as supplemental material). Because PDBu-induced downregulation of TRPM8 was blocked by incubation with PKC inhibitors, we sought to gather evidence for the possible mechanisms by which TRPM8 is modulated by PKC. Furthermore, the downregulation is likely to be attributable to reduced sensitivity of the receptor, as indicated by a rightward shift of the dose-response curve (Fig. $1 f$ ).

To understand the mechanism of downregulation, we constructed an epitope-tagged (FLAG) TRPM8. FLAG-TRPM8 was expressed in oocytes and HEK293T cells and immunoprecipitated using FLAG antibody. The isolation of TRPM8 was confirmed by the size of the protein $(126 \mathrm{kDa})$, and there was no band in untransfected cells corresponding to this size (data not shown). Oocytes and HEK cells expressing the FLAG-TRPM8 were incubated with different concentrations $(1-10 \mu \mathrm{M})$ of $\mathrm{PDBu}$. Surprisingly, PDBu treatment significantly reduced (48 \pm $2.1 \% ; n=6$ ) phosphorylation of TRPM8 (Fig. $6 a-c$ ), suggesting dephosphorylation of TRPM8. Because downregulation of TRPM8 currents was reversed by PKC inhibitors, we used these agents to determine the phosphorylation state of TRPM8. Both BIM $(500 \mathrm{nM})$ and chelerythrine $(20 \mu \mathrm{M})$ completely reversed PDBu-induced dephosphorylation (BIM, $161 \pm 20 \%, n=6$; chelerythrine, $148 \pm \pm 15 \%, n=3$ ). To further investigate the mechanism of dephosphorylation of PKC-induced downregulation of TRPM8, we used a mixture of phosphatase inhibitors (phosphatase inhibitor cocktail 1; 1/100 dilution; Sigma), which completely reversed the effect of PDBu-induced downregulation $(154 \pm 11 \% ; n=3)$ (Fig. $6 c, d)$. Interestingly, these agents exhibited a clear trend of enhancing the basal phosphorylation of TRPM8, suggesting a tonic dephosphorylation by PKC under basal conditions (Fig. $6 a, c, d$ ).

To test the specificity of the phosphatases, menthol currents were recorded from oocytes expressing TRPM8. Protein phosphatase inhibitor cocktail 1 (1:100 dilution, incubated for $>30$ min; Sigma) reversed PMA-induced downregulation (100 $\mu \mathrm{M}$ menthol; $91.5 \pm 18.6 \% ; n=7$ ) (Fig. $6 d$ ). Okadaic acid was also found to reverse $\mathrm{PDBu}$-induced downregulation. Lower concentrations $(<2 \mathrm{nM})$ of okadaic acid, which blocks protein phosphatase 2A (PP2A) had no effect, but higher concentrations of okadaic acid $(20 \mathrm{nM})$ did reverse the downregulation $(30 \mu \mathrm{M}$ menthol, 71.6 $\pm 9, n=8 ; 100 \mu \mathrm{M}$ menthol, 66.2 $\pm 20 \%, p<0.01$, 0.05 , respectively), indicating that protein phosphatase 1 (PP1) could be responsible for dephosphorylation; however, we cannot rule out the possibility of PP2A involvement. Similarly, in DRG neurons, BK-induced downregulation was completely abolished (showed a tendency for the current to increase) $(106 \pm 9.5 \% ; n=10$; $p<0.005)$ by okadaic acid $(20 \mathrm{nM})$ (Fig. $4 a$ ). Protein phosphatase $2 \mathrm{~B}$ was not likely to be involved because the specific PP2B blocker, cyclosporine ( $500 \mathrm{nM}$ ), did not reverse the downregulation by PDBu ( 1 $\mu \mathrm{M})(30 \mu \mathrm{M}$ menthol, $21 \pm 3 ; 100 \mu \mathrm{M}$ menthol, $33 \pm 8 \% ; n=5$ ). These findings suggest that activation of protein phosphatase(s) via PKC is responsible for downregulation of TRPM8.

\section{Behavioral studies to determine the role of TRPM8 in nociception}

To determine the physiological relevance of the interaction between TRPM8 and TRPV1, nocifensive behavior was examined. 
a

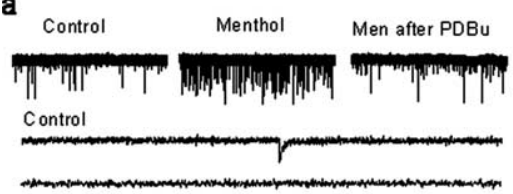

Menthol

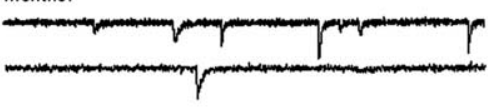

Menthol after PDBu
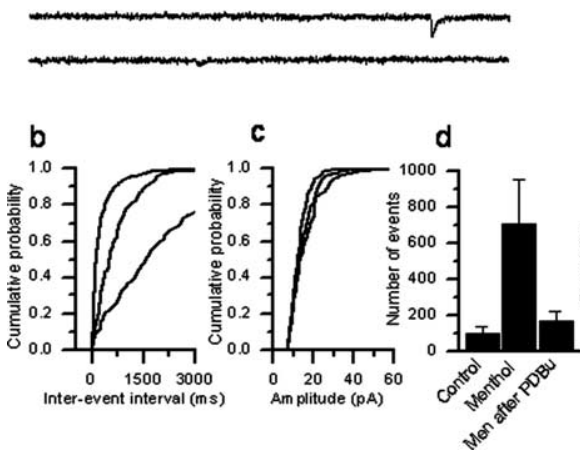

e
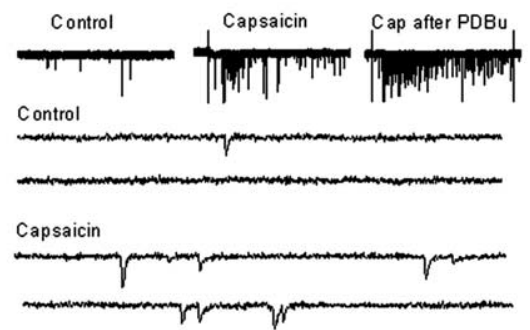

Capsaicin after PDBu
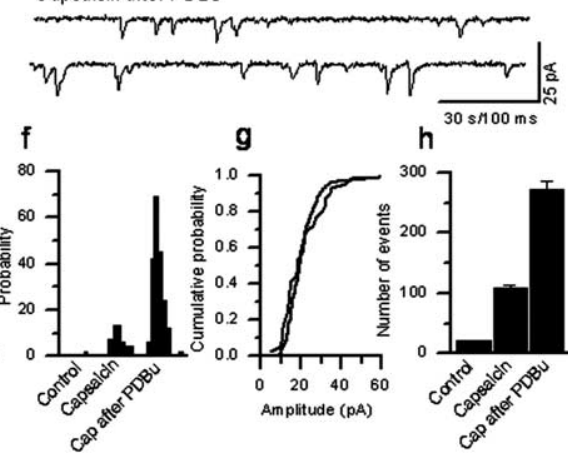

g
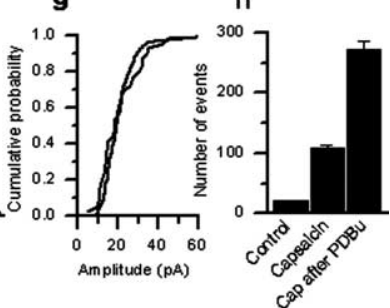

Figure 5. Modulation of menthol- and capsaicin-mediated synaptic transmission at the first sensory synapse after PKC stimulation. $\boldsymbol{a}$, Menthol-induced increases in mEPSCs were reduced by pretreatment with PDBu (control, 13; menthol, 165; menthol afterPDBu, 53). Synaptic currents are shown in higher time resolution below. $\boldsymbol{b}$, Decrease in interevent interval indicating an increase in the frequency of synaptic events, which were significantly reduced after treatment with PDBu. $c$, The increase in frequency of events was not accompanied by an increase in amplitude. $\boldsymbol{d}$, Summary graphs showing menthol-induced significant increase $(p<0.01)$ in mEPSC frequency is abolished ( $p<0.01$ ) after PDBu. $\boldsymbol{e}$, In similar experimental conditions, capsaicin-induced increases in the frequency of mEPSCs were further enhanced by PDBu (control, 7; menthol, 40; menthol after PDBu, 147). The synaptic current traces are shown in higher time resolution below. $\boldsymbol{f}$, After PDBu, the frequency increased significantly. $\boldsymbol{g}$, There was no change in amplitude before or after PDBu. $\boldsymbol{h}$, Summary graph showing capsaicin-induced increase $(p<0.01)$ in the frequency is further significantly enhanced $(p<0.01)$ by PDBu. Cap, Capsaicin; Men, menthol. Data are represented as mean \pm SEM.

The latency, duration, and number of licking and/or shaking were recorded after intraplantar injection of $20 \mu \mathrm{l}$ of capsaicin (2 $\mathrm{mM}$ ) or capsaicin plus menthol (5 $\mathrm{mM})$. The concentrations were chosen based on their respective $\mathrm{EC}_{50}$ values and previous studies in the case of capsaicin. The latency for licking or shaking was significantly increased from $6.39 \pm 1 \mathrm{~s}(n=19)$ after capsaicin alone to $11.4 \pm 0.9 \mathrm{~s}(n=23)$ after capsaicin plus menthol. The total duration of nocifensive behavior was also significantly decreased from $42.4 \pm 4.5$ to $27.3 \pm 2.5 \mathrm{~s}$. We also compared the total number of hindpaw shakes/licks for the duration of nocifensive behavior. The number of hindpaw shakes/licks was significantly decreased from $7.3 \pm 1.4$ to $3.8 \pm 0.08$ (Fig. 7). These findings suggest that activation of TRPM8 counteracts the nocifensive behavior induced by TRPV1 activation. Based on the findings of this study that TRPM8 response is reduced and TRPV1 response is increased by PKC activation, it is possible that the hyperalgesia caused by increased sensitivity of TRPV1 could be further aggravated by downregulation of TRPM8.

\section{Discussion}

The novel finding of this study is that PKC activation dramatically downregulates TRPM8 function. We demonstrate for the first time that TRPM8-mediated whole-cell and single-channel currents, transmembrane $\mathrm{Ca}^{2+}$ flux, and an increase in mEPSCs are significantly reduced. Bradykinin, an endogenous proinflammatory agent and an activator of PKC, also significantly downregulated TRPM8 in a PKC-dependent manner. This downregulation could be reversed by specific inhibitors of PKC, further suggesting modulation of TRPM8 by this enzyme. Next, we determined the mechanism of PKC-mediated downregulation of

TRPM8. Surprisingly, the downregulation was associated with a marked dephosphorylation of TRPM8, as indicated by a decrease in its levels of phospho-serine phosphorylation. Consistent with this observation, the dose-response curve of menthol shifted to the right after $\mathrm{PDBu}$, indicating reduced sensitivity of the receptor. PKC and phosphatase inhibitors reversed PKC-induced dephosphorylation and channel function. Moreover, $\mathrm{PKC}$ and phosphatase inhibitors not only prevented dephosphorylation but also enhanced the basal phosphorylation of TRPM8 as indicated by Western blots (Fig. 6). This was also seen with current measurements, in which the current amplitude increased over time following application of BIM or phosphatase inhibitors (data not shown). This may suggest that a PKC-dependent phosphatase is involved in the maintenance of basal level of phosphorylation. However, this raises the question as to how the receptor exists in a phosphorylated state to be subsequently dephosphorylated by $\mathrm{PKC}$ activation. It is possible that a low level of PKC activation may only increase phosphorylation of TRPM8, as suggested by a slight increase in current amplitude when lower concentrations of PDBu were used (Fig. 1c).

The downstream mediators of PKCinduced dephosphorylation are unclear at this time. However, this study does suggest that PKC activates a specific phosphatase, PP1, which in turn mediates dephosphorylation of TRPM8. This finding is supported by the observation that phosphatase inhibitors are able to reverse PKC-mediated downregulation of the current and dephosphorylation of the channel protein. Furthermore, in DRG neurons, BK-induced downregulation of TRPM8 was reversed by $\mathrm{PKC}$ and phosphatase inhibitors, validating the physiological relevance. The experiments using phosphatase inhibitors suggest that PP1 might be involved. PKC-activating PP1 has been shown to downregulate $\mathrm{Na}-\mathrm{K}-\mathrm{Cl}$ cotransporter in human pigmented ciliary epithelial cells (Layne et al., 2001). In contrast, TRPV1mediated membrane currents and increases in intracellular $\mathrm{Ca}^{2+}$ are significantly potentiated by $\mathrm{PDBu}$-and $\mathrm{BK}$-induced activation of PKC, as shown here and in other studies. BK has long been known to signal nociception via PKC activation. Activation of $\mathrm{PKC}$ is believed to be a critical underlying mechanism associated with hyperalgesia in inflammatory conditions (Cesare et al., 1999a,b; Khasar et al., 1999; Premkumar and Ahern, 2000; Numazaki et al., 2002; Sugiura et al., 2002; Wang et al., 2004). We are able to show that $\mathrm{BK}$ mimics the actions of $\mathrm{PDBu}$ in modulating TRPM8 and TRPV1 functions in DRG neurons.

Activation of TRPM8 and TRPV1 robustly increases synaptic transmission (Baccei et al., 2003; Tsuzuki et al., 2004). We show in this study that PKC reciprocally modulates synaptic transmission mediated by TRPM8 and TRPV1. The menthol-induced increase in the frequency of mEPSCs was significantly reduced, whereas the capsaicin-induced increase in frequency was significantly augmented. It is important to note that only the frequency, but not the amplitude, was altered, suggesting a presynaptic site 
a

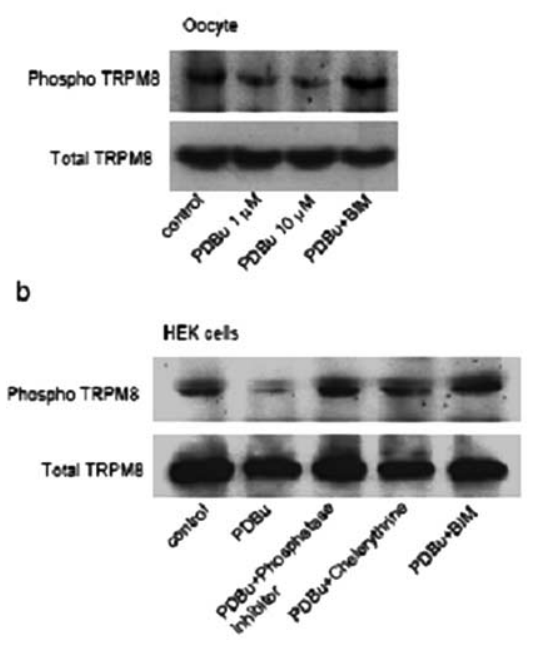

c

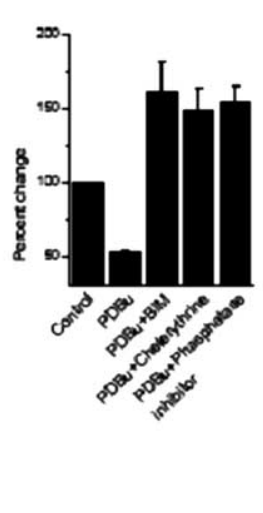

d
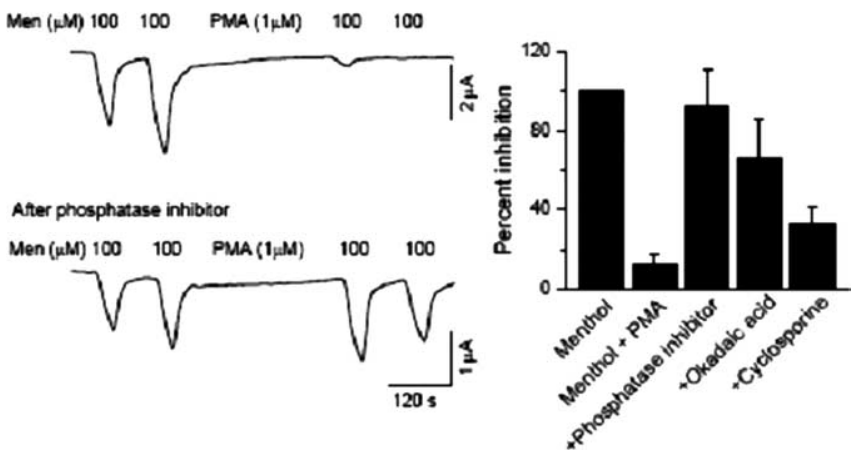

Figure 6. Activation of PKC reduces TRPM8 phosphorylation. $\boldsymbol{a}$, In oocytes, PDBu treatment dose dependently reduces phosphorylation (phospho TRPM8) of immunoprecipitated FLAGTRPM8, which is reversed by pretreatment with BIM. $\boldsymbol{b}$, HEK293T cells transiently transfected with FLAG-TRPM8 and treated with PDBu alone and in the presence of different PKC inhibitors, BIM (500 nM) and chelerythrine $(20 \mu \mathrm{M})$, or phosphatase inhibitor mixture show that PDBuinduced reduction in phosphorylated TRPM8 could be reversed by PKC and phosphatase inhibitors. c, Summary graph normalized to total TRPM8 levels showing significant decrease ( $p<$ 0.001 ) in phosphorylated TRPM8. PKC inhibitors (BIM, chelerythrine) and phosphatase inhibitors significantly reversed ( $p<0.005, p<0.005$, and $p<0.005$, respectively) the effect of $\mathrm{PDBu}$ and significantly increased basal phosphorylation. $\boldsymbol{d}, \mathrm{PMA}$-induced downregulation is reversed $(p<0.005)$ by pretreatment with phosphatase inhibitor mixture and okadaic acid $(p<0.05)$ but not by cyclosporine. Cap, Capsaicin. Data are represented as mean \pm SEM.

of action. TRPM8- and TRPV1-induced modulation of synaptic transmission is seen only in DRG-DH neuronal cocultures and not in DH-only cultures, suggesting involvement of these receptors located on the central terminal of sensory neurons. Phorbol esters have been shown to augment evoked and miniature EPSCs by increasing the apparent $\mathrm{Ca}^{2+}$ sensitivity of vesicle fusion (Lou et al., 2005). In our experiments, PDBu-induced increase in mEPSCs is readily reversible. However, we are able to record an increase and decrease in TRPV1- and TRPM8-mediated synaptic current, respectively, after washout of PDBu effect. This observation suggests PKC-mediated effect of PDBu (phosphorylation of TRP channels) lasts longer than the direct action of PDBu binding to munc-13 (Leenders and Sheng, 2005). Modulation of synaptic transmission by neurotransmitters and neuropeptides plays a significant role. In this context, BK acting via BK2 receptors and glutamate activating its metabotropic receptors located on the central terminals of sensory neurons might play a role in modulating synaptic transmission at the first sensory synapse. Al-
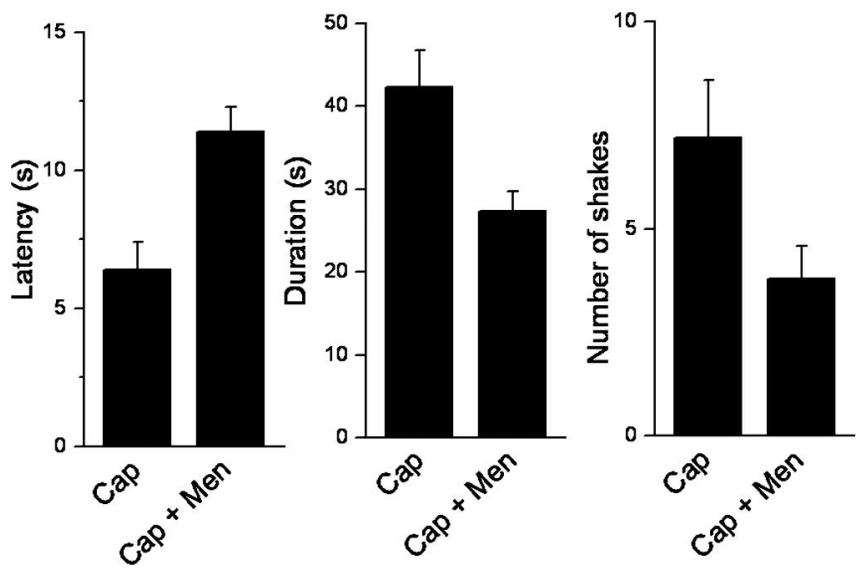

Figure 7. Capsaicin-induced nocifensive behavior is reduced by coadministration with menthol. Latency, duration, and number of licks and/or shakes of the injected hindpaw were determined after intraplantar injection of $20 \mu$ lof capsaicin $(2 \mathrm{~mm})$ or capsaicin plus menthol $(5 \mathrm{mM})$. After coadministration of capsaicin plus menthol, the latency for licks and/or shakes was significantly increased from $6.39 \pm 1 \mathrm{~s}(n=19)$ to $11.4 \pm 0.9 \mathrm{~s}(n=23 ; p<0.01)$. The duration of licks and/or shakes was also significantly decreased from $42.4 \pm 4.5$ to $27.3 \pm 2.5 \mathrm{~s}$ ( $p<$ $0.01)$. Subsequently, we also counted the number of hindpaw licks and/or shakes with a cutoff time of $2 \mathrm{~min}$. The number of characteristic hindpaw shakes was decreased significantly from $7.3 \pm 1.4$ to $3.8 \pm 0.08(p<0.05)$. These findings suggest that there is a functional interaction between TRPM8 and TRPV1. Cap, Capsaicin; Men, menthol. Data are represented as mean \pm SEM

though $<8 \%$ of DRG neurons responded to menthol and $12 \%$ responded capsaicin in $\mathrm{Ca}^{2+}$ imaging and whole-cell voltageclamp experiments, a much greater proportion of voltageclamped DH neurons responded to menthol and capsaicin while recording synaptic currents from DRG-DH cocultures, indicating the extent of DRG neuronal dendritic arborization. This observation raises the possibility that not only TRPM8 and TRPV1 functions could be altered, but the number of their respective synaptic connections between DRG-DH neurons may also be modified in certain conditions like chronic pain. Modulation of TRP channels is much more relevant at this synapse because of the reciprocal nature of regulation of TRPM8 and TRPV1 by PKC we observed in this study.

Sensitization of TRPV1 by inflammatory mediators acting via $\mathrm{PKC}$, protein kinase $\mathrm{A}$, and receptor tyrosine kinase has been shown to underlie hyperalgesia (Malmberg et al., 1997; Lopshire and Nicol, 1998; Cesare et al., 1999a,b; Khasar et al., 1999; Premkumar and Ahern, 2000; Chuang et al., 2001; Bhave et al., 2002; Numazaki et al., 2002; Wang et al., 2004). Here, we have demonstrated downregulation of TRPM8 by dephosphorylation of the receptor by activation of PKC. In normal conditions, TRPM8, which is almost exclusively expressed in a subset of neurons, may mediate a cool/soothing sensation and could function to counter the painful stimulus via activation of TRPV1. Indeed, we observed that intraplantar injection of menthol along with capsaicin significantly reduced nocifensive behavior compared with injection of capsaicin alone, suggesting an interaction between sensory functions of TRPM8 and TRPV1 (Fig. 7). In chronic pain conditions, increased levels of inflammatory mediators/trophic factors could induce coexpression of TRPM8 and TRPV1 in the same neuron that may jeopardize the counter-balance mechanism we are proposing. Treatment with NGF has been shown to induce coexpression of TRPM8 and TRPV1 in DRG neurons (Story et al., 2003). The usefulness of NGF antibody, which is being pursued as a potential treatment for chronic pain conditions, may partly be a result of its ability to thwart coexpression (Owolabi et al., 1999). 
Reciprocal modulation of TRPM8 and TRPV1 by $\mathrm{PIP}_{2}$ has been described previously (Liu and Qin, 2005). In heterologous expression systems, TRPM8 is activated, whereas TRPV1 is tonically inhibited by $\mathrm{PIP}_{2}$. Hydrolysis of $\mathrm{PIP}_{2}$ by activating phospholipase $\mathrm{C}$ downregulates TRPM8 channel function but robustly upregulates TRPV1 function (Chuang et al., 2001). We observed in a native system using dissociated DRG neurons that BK-induced downregulation of TRPM8 and upregulation of TRPV1 could almost completely be reversed by a PKC inhibitor.

Our findings indicate that PKC activation not only sensitizes TRPV1 but also downregulates TRPM8 activity. Hence, thermal hyperalgesia caused by PKC-induced sensitization of TRPV1 by inflammatory mediators could paradoxically be further aggravated by downregulation of TRPM8, activation of which provides the much needed cool/soothing sensation. Inhibition of PKCmediated phosphorylation is currently being tried as a therapeutic strategy to relieve hyperalgesia resulting from diverse pathophysiological conditions (Wheeler, 2003). The effectiveness of PKC inhibitors in certain painful conditions may be attributable to a dual action of preventing sensitization of TRPV1 but at the same time preserving functions of TRPM8. Furthermore, these changes occur at both peripheral nerve terminals as well as the first sensory synapse at the level of the spinal cord. TRPM8 and TRPV1 located at the peripheral and central terminals and their modulation by PKC could thus play a significant role in controlling the gain of painful input to the brain.

\section{References}

Baccei ML, Bardoni R, Fitzgerald M (2003) Development of nociceptive synaptic inputs to the neonatal rat dorsal horn: glutamate release by capsaicin and menthol. J Physiol (Lond) 549:231-242.

Bhave G, Zhu W, Wang H, Brasier DJ, Oxford GS, Gereau RW IV (2002) cAMP-dependent protein kinase regulates desensitization of the capsaicin receptor (VR1) by direct phosphorylation. Neuron 35:721-731.

Birder LA, Nakamura Y, Kiss S, Nealen ML, Barrick S, Kanai AJ, Wang E, Ruiz G, De Groat WC, Apodaca G, Watkins S, Caterina MJ (2002) Altered urinary bladder function in mice lacking the vanilloid receptor TRPV1. Nat Neurosci 5:856-860.

Caterina MJ, Schumacher MA, Tominaga M, Rosen TA, Levine JD, Julius D (1997) The capsaicin receptor: a heat-activated ion channel in the pain pathway. Nature 389:816-824.

Cesare P, Dekker LV, Sardini A, Parker P, McNaughton PA (1999a) Specific involvement of PKC-epsilon in sensitization of the neuronal response to painful heat. Neuron 23:617-624.

Cesare P, Moriondo A, Vellani V, McNaughton PA (1999b) Ion channels gated by heat. Proc Natl Acad Sci USA 96:7658-7663.

Chuang HH, Prescott ED, Kong H, Shields S, Jordt SE, Basbaum AI, Chao MV, Julius D (2001) Bradykinin and nerve growth factor release the capsaicin receptor from PtdIns(4,5)P2-mediated inhibition. Nature 411:957-962.

Clapham DE (2003) TRP channels as cellular sensors. Nature 426:517-524.

Huang SM, Bisogno T, Trevisani M, Al-Hayani A, De Petrocellis L, Fezza F, Tognetto M, Petros TJ, Krey JF, Chu CJ, Miller JD, Davies SN, Geppetti P, Walker JM, Di Marzo, V (2002) An endogenous capsaicin-like substance with high potency at recombinant and native vanilloid VR1 receptors. Proc Natl Acad Sci USA 99:8400-8405.

Hwang SW, Cho H, Kwak J, Lee SY, Kang CJ, Jung J, Cho S, Min KH, Suh YG, Kim D, Oh U (2000) Direct activation of capsaicin receptors by products of lipoxygenases: endogenous capsaicin-like substances. Proc Natl Acad Sci USA 97:6155-6160.

Julius D, Basbaum AI (2001) Molecular mechanisms of nociception. Nature 413:203-210.

Khasar SG, Lin YH, Martin A, Dadgar J, McMahon T, Wang D, Hundle B, Aley KO, Isenberg W, McCarter G, Green PG, Hodge CW, Levine JD, Messing RO (1999) A novel nociceptor signaling pathway revealed in protein kinase C epsilon mutant mice. Neuron 24:253-260.

Layne J, Yip S, Crook RB (2001) Down-regulation of Na-K-Cl cotransport by protein kinase $\mathrm{C}$ is mediated by protein phosphatase 1 in pigmented ciliary epithelial cells. Exp Eye Res 72:371-379.

Leenders AGM, Sheng Z-H (2005) Modulation of neurotransmitter release by second messenger-activated protein kinases: implications for presynaptic plasticity. Pharmacol Ther 105:69-84.

Liu B, Qin F (2005) Functional control of cold- and menthol-sensitive TRPM8 ion channels by phosphatidylinositol 4,5-bisphosphate. J Neurosci 25:1674-1681.

Lopshire JC, Nicol GD (1998) The cAMP transduction cascade mediates the prostaglandin E2 enhancement of the capsaicin-elicited current in rat sensory neurons: whole-cell and single-channel studies. J Neurosci 18:6081-6092.

Lou X, Scheuss V, Schneggenbuger R (2005) Allosteric modulation of the presynaptic $\mathrm{Ca}^{2+}$ sensor for vesicle fusion. Nature 435:497-501.

Malmberg AB, Brandon EP, Idzerda RL, Liu H, McKnight GS, Basbaum AI (1997) Diminished inflammation and nociceptive pain with preservation of neuropathic pain in mice with a targeted mutation of the type I regulatory subunit of cAMP-dependent protein kinase. J Neurosci 17:7462-7470.

Manzini S (1992) Bronchodilatation by tachykinins and capsaicin in the mouse main bronchus. Br J Pharmacol 105:968-972.

McKemy DD, Neuhausser WM, Julius D (2002) Identification of a cold receptor reveals a general role for TRP channels in thermosensation. $\mathrm{Na}$ ture 416:52-58.

Mezey E, Toth ZE, Cortright DN, Arzubi MK, Krause JE, Elde R, Guo A, Blumberg PM, Szallasi A (2000) Distribution of mRNA for vanilloid receptor subtype 1 (VR1), and VR1-like immunoreactivity, in the central nervous system of the rat and human. Proc Natl Acad Sci USA 97:3655-3660.

Minke B, Cook B (2002) TRP channel proteins and signal transduction. Physiol Rev 82:429-472.

Montell C (2005) The TRP superfamily of cation channels. Sci STKE. 272:re3.

Numazaki M, Tominaga T, Toyooka H, Tominaga M (2002) Direct phosphorylation of capsaicin receptor VR1 by protein kinase Cepsilon and identification of two target serine residues. J Biol Chem 277:13375-13378.

Owolabi JB, Rizkalla G, Tehim A, Ross GM, Riopelle RJ, Kamboj R, Ossipov M, Bian D, Wegert S, Porreca F, Lee DK (1999) Characterization of antiallodynic actions of ALE-0540, a novel nerve growth factor receptor antagonist, in the rat. J Pharmacol Exp Ther 289:1271-1276.

Peier AM, Moqrich A, Hergarden AC, Reeve AJ, Andersson DA, Story GM, Earley TJ, Dragoni I, McIntyre P, Bevan S, Patapoutian A (2002) A TRP channel that senses cold stimuli and menthol. Cell 108:705-715.

Premkumar LS, Ahern GP (2000) Induction of vanilloid receptor channel activity by protein kinase C. Nature 408:985-990.

Reid G, Babes A, Pluteanu F (2002) A cold- and menthol-activated current in rat dorsal root ganglion neurones: properties and role in cold transduction. J Physiol (Lond) 545:595-614.

Story GM, Peier AM, Reeve AJ, Eid SR, Mosbacher J, Hricik TR, Early TJ, Hergarden AC, Andersson DA, Hwang SW, McIntyre P, Jegla T, Bevan S, Patapoutian A (2003) ANKTM1, a TRP-like channel expressed in nociceptive neurons, is activated by cold temperatures. Cell 112:819-829.

Sugiura T, Tominaga M, Katsuya H, Mizumura K (2002) Bradykinin lowers the threshold temperature for heat activation of vanilloid receptor 1 . J Neurophysiol 2002 88:544-548.

Tominaga M, Caterina MJ, Malmberg AB, Rosen TA, Gilbert H, Skinner K, Raumann BE, Basbaum AI, Julius D (1998) The cloned capsaicin receptor integrates multiple pain-producing stimuli. Neuron 21:531-543.

Tsavaler L, Shapero MH, Morkowski S, Laus R (2001) Trp-p8, a novel prostate-specific gene, is up-regulated in prostate cancer and other malignancies and shares high homology with transient receptor potential calcium channel proteins. Cancer Res 61:3760-3769.

Tsuzuki K, Xing H, Ling J, Gu JG (2004) Menthol-induced $\mathrm{Ca}^{2+}$ release from presynaptic $\mathrm{Ca}^{2+}$ stores potentiates sensory synaptic transmission. J Neurosci 24:762-771.

Wang Y, Kedei N, Wang M, Wang QJ, Huppler AR, Toth A, Tran R, Blumberg PM (2004) Interaction between protein kinase Cmu and the vanilloid receptor type 1. J Biol Chem 279:53674-53682.

Wheeler GD (2003) Ruboxistaurin (Eli Lilly). Drugs 6:159-163.

Zygmunt PM, Petersson J, Andersson DA, Chuang H, Sorgard M, Di Marzo V, Julius D, Hogestatt ED (1999) Vanilloid receptors on sensory nerves mediate the vasodilator action of anandamide. Nature 400:452-457. 